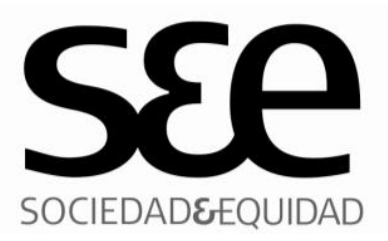

SOCIEDADEEQUIDAD

\section{Análise preditiva de pobreza e vulnerabilidades sociais no âmbito municipal: o caso de Minas Gerais, Brasil}

Predictive analysis of poverty and social vulnerabilities at the municipal level: the case of Minas Gerais, Brazil

$\begin{array}{ll}\text { Nombre: } & \text { Alexander Cambraia Nascimento } \\ & \text { Vaz (1) } \\ \text { Filiación: } & \text { Universidad Federal de Minas Gerais } \\ \text { País: } & \text { Brasil } \\ \text { Correo: } & \text { cambraia04@gmail.com }\end{array}$

\title{
Resumen
}

El artículo trata sobre un modelo de mapeo y escalonamiento de la vulnerabilidad social de los municipios a partir de las características de subconjuntos de poblaciones vulnerables y de distinciones socio-económicas y de acceso a los servicios. Su principal objetivo es la generación de perfiles de vulnerabilidad de municipios cuya base se basa no sólo en las características intrínsecas de estos subgrupos socioeconómicos, sino también las especificidades sociodemográfica de las regiones que habitan cada uno. Se sugiere que las regiones congregan diferentes factores que influyen en la reproducción de las vulnerabilidades de manera diferente en diferentes sub-poblaciones $y$, en este sentido, la producción de las políticas públicas en este campo debe lidiar con las complejidades socio demográfico de cada región y en cada acción de intervención propuesta. Tomando como objeto de estudio el Estado de Minas Gerais (Brasil) y adoptando dos principales fuentes de datos, el censo del 2000 y el último PNAD, se pretende realizar un análisis descriptivo de los grupos vulnerables por micro-regiones del Estado, a través de micro-estado, aplicándose por lo tanto, el método de análisis factorial y el GOM (Grado de afiliación). Con base en esto, se llevará a cabo un análisis de vulnerabilidad municipal a partir de los subgrupos y las características de los

\footnotetext{
${ }^{1}$ El autor es doctorando en Ciencia Política por la UFMG/Brasil. Es además Consultor de la Organización de las Naciones Unidas para la Educación, la Ciencia y la Cultura, UNESCO. Sus líneas de investigación son: análisis y validación de políticas públicas, políticas sociales y modelaje con microdados.
} 




municipios en relación al contexto socioeconómico y el acceso a los servicios, utilizando para ello, un análisis de regresión multivariante que permite predecir tipos de vulnerabilidades de las características observadas.

\section{Palabras Claves}

Vulnerabilidad Social, Estadística Multivariada, Desarrollo Social.

\section{Resumo}

O trabalho lida com um modelo de mapeamento e escalonamento da vulnerabilidade social de municípios a partir de características de subconjuntos populacionais vulneráveis e de distinções sócio demográficas e de acesso a serviços. Seu objetivo principal consiste na geração de perfis de vulnerabilidade de municípios cuja base se assente não apenas nas características socioeconômicas intrínsecas destes subgrupos populacionais, mas, também, nas especificidades sócio demográficas das regiões que habitam cada qual. Sugere-se que regiões distintas congregam de fatores distintos que influenciam de maneira diferenciada a reprodução das vulnerabilidades nos diversos subconjuntos populacionais e, neste sentido, a produção de políticas públicas neste campo deve lidar com as complexidades sócio demográficas de cada região em cada ação de intervenção proposta. Tomando por objeto de estudo o Estado de Minas Gerais (Brasil) e adotando duas principais fontes de dados, o Censo Demográfico 2000 e as últimas PNADs, pretende-se realizar uma análise descritiva dos grupos vulneráveis por microrregião do Estado, aplicando-se, para tanto, na análise fatorial e no método GoM (Grade of Membership). Com base nisso, empreender-se-á uma discussão da vulnerabilidade municipal a partir dos subgrupos e das características dos municípios no tocante ao contexto socioeconômico e ao acesso a serviços, utilizando-se, para tanto, de uma análise de regressão multivariada que permita predizer tipos de vulnerabilidades a partir das características observadas.

\section{Palavras-chave}

Vulnerabilidade Social, Estatística Multivariada, Desenvolvimento Social. 


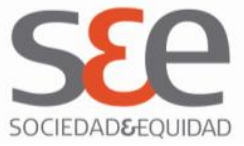

\begin{abstract}
The paper deals with a model of scheduling and mapping the social vulnerability of municipalities from subsets of vulnerable population characteristics and sociodemographic distinctions and access to services. Its main objective is the generation of vulnerability profiles of municipalities based upon not only the intrinsic characteristics of these socioeconomic subgroups, but also on the specific sociodemographic regions inhabiting each. It is suggested that different regions bring together different factors that influence differently the reproduction of vulnerabilities in different sub-populations and in this sense, the production of public policies in this field must deal with the sociodemographic complexities of each region in each intervention action proposal. Taking as an object of study the State of Minas Gerais (Brazil) and adopting two main sources of data, the Census 2000 and the last PNAD, we intend to perform a descriptive analysis of vulnerable groups by micro-state through the factor analysis method and the GoM (Grade of Membership). Based on this, it will undertake a discussion of municipal vulnerability from subgroups and characteristics of municipalities with regard to socioeconomic background and access to services, using to this end, a multivariate regression analysis that allows a prediction of types of vulnerabilities from the characteristics observed.
\end{abstract}

\title{
Keywords
}

Social Vulnerability, Multivariate Statistics, Social Development.

\section{Introdução}

O objetivo deste trabalho é construir um modelo preditivo de mapeamento e escalonamento da "vulnerabilidade social" de municípios brasileiros, a partir, por um lado, de características de subconjuntos populacionais ditos vulneráveis e, por outro, de distinções socioeconômicas e de acesso a bens e serviços públicos. 0 processo de planejamento público tem se revelado significativo sob diversos pontos de vista, seja material, econômico, político ou mesmo social (Rowe e Frewer, 2004; Pires e Vaz, 2010; Rossi e Lipsey, 2004). Especialmente nos últimos anos, parece que a área social tem sofrido dada inflexão teórico-analítica face novas concepções e definições em torno de conceitos fundamentais para o campo, como no caso de transmudações dos conceitos de risco, violações e, principalmente, de vulnerabilidades sociais (Carneiro, 2005; Castro e Abramovay, 2002). A concepção de riscos e violações de direitos tem perpassado a 


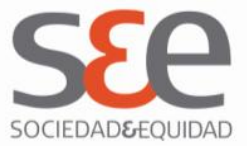

variável renda como substrato principal e estruturado noções mais complexas acerca da condição de exclusão e marginalização dos indivíduos, como a multidimensionalidade e a multicausalidade da condição de vulnerável (Worthen e Sanders, 2004).

Tal complexificação tem oferecido desafios significativos para se pensar programas e/ou serviços de ordem social, isto é, ações que pretendam trabalhar com públicos vulneráveis, especialmente no sentido de amenizá-la e/ou erradica-la, como no caso das situações de pobreza e miséria (Cavalcanti, 2006). As vulnerabilidades se manifestariam não apenas em função da carência de recursos e/ou capacidades dos indivíduos, mas seriam extensivas e teriam capacidade de se reproduzir ao longo de suas redes relacionais, sejam elas de caráter profissional, ou de amizade, por exemplo. Seu enfrentamento, assim, tenderia a se afigurar incompleto caso tivesse o foco restrito aos indivíduos, famílias e/ou grupos ditos mais vulneráveis, porque lhe faltaria uma ótica contextual capaz de abarcar este caráter espaço-temporal de reprodutibilidade.

0 argumento base que permeia o trabalho é que a multimensionalidade $\mathrm{e}$ multicausalidade das vulnerabilidades sociais tem raízes não apenas no aspecto de carência e privação de renda e de capacidades dos indivíduos, mas inclui também uma perspectiva de reprodução espaço-temporal que a faz estender sobre todas as redes de relacionamento destes últimos, especialmente daquelas mais próximas. Sugere-se, nessa linha, que contextos distintos são dotados de fatores distintos que podem influenciar diferentemente a caracterização e a reprodução das vulnerabilidades. Com isso, grupos sociais ditos homogêneos, como mulheres, crianças, idosos, dentre outros, não devem ser tratados sob tal viés por políticas públicas interventivas porque seus respectivos grau e tipo de vulnerabilidade tendem a depender, na verdade, muito mais de sua localização contextual do que de seu pertencimento a estes subconjuntos clássicos. Políticas públicas sociais, assim, devem enfrentar o desafio de não apenas tratar de maneira diferenciada grupos distintos congregados num mesmo contexto, mas, também, de empregar ações distintas a um mesmo grupo social a guisa de sua localização em diferentes contextos.

Como forma de lidar com a questão, duas opções metodológicas são feitas. Primeiro, toma-se por unidade de análise o município como proxy para a variável contextual, em função tanto da disponibilidade de dados, concernentes, neste caso, aos bancos de microdados do Censo Demográfico 2000, quanto de sua intrínseca importância para o planejamento público de uma forma geral. Em segundo lugar, toma-se por objeto de estudo o Estado de Minas Gerais, dada a heterogeneidade dos municípios que o compõem, seja em termos econômicos, seja em termos sócio-políticos. 0 foco principal de investigação consiste na geração de perfis de vulnerabilidade de municípios e, subsequentemente, na composição de um modelo de regressão multivariado preditivo destes perfis, cuja base se assente não apenas nas características socioeconômicas intrínsecas dos subgrupos populacionais, mas tome também por proxy analítica e de 


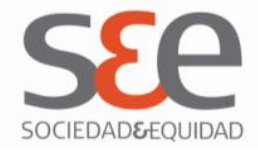

composição do conceito as especificidades sócio demográficas dos contextos nos quais se inserem cada qual.

0 trabalho segue organizado da seguinte forma. A primeira seção realiza breve contextualização da temática de proteção e planejamento social no Brasil, especialmente sob a ótica da complexificação social. Na segunda parte são descritos os passos e as técnicas metodológicas para o teste da hipótese de trabalho, operacionalizando $o$ conceito de vulnerabilidade social em dimensões e variáveis/indicadores específicos ligados às principais definições teóricas do termo e lidando com os determinantes do fenômeno, tomados como as principais variáveis contextuais diferenciadoras dos municípios. Na terceira seção são aplicadas as técnicas estatísticas de geração de perfis de vulnerabilidade e de composição do modelo preditivo.

\section{Contextos e vulnerabilidade}

Ao longo das últimas décadas, o Brasil tem se transformado muito mais num país urbano do que rural. Dados dos Censos e PNADS do IBGE revelam que apenas entre 1991 e 2005, a taxa média de urbanização de país passou de $75,6 \%$ para $82,8 \%$. Não obstante esse crescimento significativo das taxas de urbanização no país, é possível dizer, pelo menos no caso do Brasil, que o crescimento dos centros urbanos de uma forma geral não foi acompanhado de políticas de planejamento específicas que o disciplinassem. As condições urbanas das cidades brasileiras, assim, redundaram, por fim, naquilo que se convencionou chamar de "exclusão territorial".

Esse fenômeno de exclusão tem sido tratado, ao longo dos últimos anos na esfera do planejamento público, sob a égide do conceito de "vulnerabilidade social", geralmente associado às situações de extrema pobreza e degradação humana a que está sujeita grande parte da população. Segundo Carneiro (2005), o termo vulnerabilidade tem sido tratado pela literatura em três sentidos distintos. 0 primeiro deles relaciona vulnerabilidade à ausência ou escassez de renda das famílias ou indivíduos, dadas pela sua inserção precária ou não-inserção no mercado de trabalho. O segundo sentido acrescenta à escassez ou ausência de renda a falta de acesso, ou acesso precário, das famílias e/ou indivíduos, a serviços e bens sociais básicos, tais como, moradia, saúde, educação, saneamento básico, energia elétrica etc., em virtude da ausência ou nãoefetividade das políticas públicas em prover estes bens e serviços de forma equânime a todos os segmentos da população. 0 terceiro sentido que a literatura tem atribuído ao conceito de vulnerabilidade relaciona-o não apenas à renda ou ao usufruto de bens e serviços sociais, mas, principalmente, às capacidades das famílias e indivíduos. A pobreza, nessa perspectiva, "é definida como privação de capacidades, sendo pobres aqueles que carecem de capacidades básicas para operarem no meio social, que 


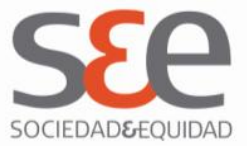

carecem de oportunidades para alcançar níveis minimamente aceitáveis de realizações, o que pode independer da renda que os indivíduos detêm” (Carneiro, 2005: 71).

O que se busca esclarecer com toda essa discussão é que, na verdade, as ações de monitoramento revelam-se, ao mesmo tempo, necessárias, mas complexas, desde que empreendidas sob uma perspectiva de garantia de robustez e consistência. Não é difícil notar que o principal desafio concernente à estruturação de políticas públicas na área social está ligado ao prognóstico das situações de vulnerabilidade social, considerando esta última um fenômeno multidimensional e multicausado. Considerando esse fato, algumas questões são passíveis de serem estruturadas, como: qual tipo de perfil de públicos-alvo deve ser tratado pelos programas de assistência social? Considerando os municípios brasileiros, qual a probabilidade de incidência de vulnerabilidade social considerada em seu espectro amplo, isto é, para os diversos públicos da área?

\section{Metodologia}

A principal questão que norteia o presente trabalho concerne aos desafios imputados à gestão pública advindos da multidimensionalidade do fenômeno da vulnerabilidade social. São duas as principais hipóteses trabalhadas. Em primeiro lugar, o perfil dos públicos da assistência social varia conforme os seus respectivos contextos de inserção (Beato e Reis, 2000; Cano e Soares, 2002; Farah, 2004; Lavinas e Nicoll, 2006). A guisa das condições socioeconômicas dos municípios brasileiros, por exemplo, um mesmo tipo de público estará sujeito a condições diferenciadas de vulnerabilidade, bem como, dentro de um mesmo município, distintos públicos estarão sujeitos a diferentes incidências do fenômeno. Isso quer dizer que as políticas de assistência social direcionadas a públicos-alvo específicos devem levar em consideração as especificidade decorrentes dos contextos nos quais estes públicos se encontram inseridos e que definem, em última instância, os tipos de vulnerabilidades aos quais eles estarão sujeitos e prementes de assistência.

A segundo hipótese central de pesquisa é que, com base na variável contextual como substrato de incidência de vulnerabilidades, os municípios brasileiros estarão sujeitos a probabilidades específicas de incidência de distintos tipos e graus do fenômeno (Andrade e Lisboa, 2000; Sapori e Wanderley, 2001). Como os municípios se diferenciam em termos sociais, políticos e econômicos, não é difícil prever que eles "oferecem" aos diferentes públicos incidências distintas de vulnerabilidades sociais, especialmente em termos de tipos e intensidades.

Para o tratamento de ambas as hipóteses de pesquisa, alguns procedimentos são desenvolvidos nas próximas seções, tendo por base utilização dos microdados do Censo Populacional referente ao ano 2000. Em primeiro lugar, é preciso estabelecer um padrão 


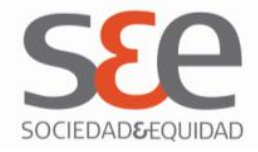

de mensuração do conceito de vulnerabilidade social, dado como variável dependente no modelo a ser estruturado. Essa mensuração é realizada com base na escolha de variáveis e indicadores que, segundo a literatura pertinente, tendem a expressar de maneira concreta o conceito. Em segundo lugar, estabelecer os principais determinantes do fenômeno, através, especificamente, da escolha de variáveis contextuais capazes, sugere-se, de cumprirem tal papel. A terceira etapa do processo consiste na construção dos perfis de vulnerabilidade dos públicos-alvo segundo contextos de inserção, tomando por objeto, para tanto, os municípios do Estado de Minas Gerais. Duas técnicas são utilizadas nesse caso, sendo a Análise Fatorial - AF - e o método Grade ofMembership GoM.

A análise fatorial permite o exame da estrutura correlações entre um grande número de variáveis, definindo um conjunto de dimensões latentes comuns, chamados de fatores (Hair et al, 2005). Os resultados apresentam o grau que cada variável é explicada por cada fator. Os objetivos principais da análise fatorial são diminuir a dimensionalidade das variáveis e ao mesmo tempo, gerar um novo instrumento de explicação, que será mais parcimonioso e poderá ser utilizado em substituição às variáveis individuais originais para se explicar um fenômeno. Além disso, permite também a organização hierarquizada da informação disponível. Após a criação dos subconjuntos vulneráveis para cada público-alvo considerado, é preciso criar um perfil de vulnerabilidade dos próprios municípios de Minas Gerais, incluindo aí, portanto, as variáveis e indicadores de caráter contextual. 0 método a ser utilizado nessa linha é o GOM, quese baseia na teoria dos conjuntos nebulosos e, no âmbito das análises discriminantes, estrutura-se pela estimativa de verossimilhança do i-ésimo indivíduo na l-ésima categoria da j-ésima variável.

A utilização dos métodos acima irá criar perfis de referência caracterizados por variáveis de vulnerabilidade e por variáveis contextuais (Hair et al, 2005). Nessa linha, será possível utilizá-los como padrão para categorização dos municípios mineiros e a identificação dos tipos de vulnerabilidade mais prementes em seus respectivos territórios. Nesse sentido, o quarto procedimento a ser seguido no trabalho consiste na estimação de uma função de regressão capaz de predizer a probabilidade de incidência dos municípios a dados perfis de vulnerabilidade a partir dos seus próprios perfis socioeconômicos. Nesse caso, o conjunto de subgrupos populacionais vulneráveis gerados a partir da análise fatorial é tomado como variável dependente e as variáveis contextuais, correlacionadas através do método GoM, são tomadas como variáveis independentes. Assim, será possível estimar, para qualquer município do país, qual o tipo mais provável de vulnerabilidade a que está sujeita sua população a partir de informações sobre suas próprias características socioeconômicas. 


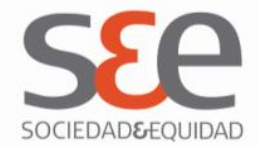

Mensuração da vulnerabilidade social: definições e aportes

O primeiro procedimento operacional a ser seguido no trabalho concerne à mensuração da vulnerabilidade social nos municípios mineiros. Para trata-lo de maneira efetiva, a literatura pertinente tem sugerido uma série de variáveis e indicadores que seriam capazes de operacionaliza-lo (Cerqueira e Lobão, 2003; Draibe, 2001; PNAS, 2004). A Tabela do Anexo A correlaciona as variáveis trazidas à baila nessa linha, tentando captar os efeitos da vulnerabilidade social para aqueles públicos-alvo ditos mais vulneráveis na seara da assistência social de uma maneira geral (Carneiro, 2005).

É possível perceber através da análise dos indicadores elencados que a vulnerabilidade social é tratada não apenas sob a ótica da renda, mas, também, a partir de características específicas dos públicos que os tornam vulneráveis. Apenas como ilustração, no caso de famílias, por exemplo, leva-se em consideração tanto a sua origem, rural ou urbana, quanto a sua composição, como aquelas chefiadas apenas por mulheres, ou, ainda, aquelas cuja razão de dependência supere os $75 \%$. Já no caso de crianças, leva-se em consideração, dentre um conjunto de fatores, a capacidade das mães de proverem bem-estar aos seus filhos, por exemplo. Além dessas informações, é importante salientar o aspecto de distribuição dos municípios por quartis de prevalência dos indicadores, tal como indicado nas colunas correlatas.

A utilização da técnica de análise fatorial gerou subgrupos de vulnerabilidade, com características próprias, para cada público-alvo considerado. Como já dito, a importância da geração destes fatores consiste na estruturação de dimensões analíticas conjunturais, potencializando a interpretação dos resultados e a mensuração do fenômeno estudado. Cada fator gerado foi classificado em termos de graus de severidade da vulnerabilidade social, segundo os conceitos abaixo:

- VSB - Vulnerabilidade social baixa

- VSMB - Vulnerabilidade social média-baixa

- VSMA - Vulnerabilidade social média-alta

- VSA - Vulnerabilidade social alta

\section{Determinantes da vulnerabilidade social: contextos e medidas}

Tendo especificado os principais componentes de mensuração da vulnerabilidade social, o segundo procedimento a ser seguido concerne à operacionalização dos fatores determinantes do fenômeno. A principal hipótese deste trabalho é de que estes fatores estariam ligados em grande medida a aspectos contextuais dos municípios brasileiros, o que implicaria probabilidades diferentes de graus e tipos de incidência de vulnerabilidades sociais a guisa das características socioeconômicas das cidades 


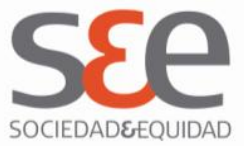

brasileiras (Worthen e Sanders, 2004; Lavinas e Nicoll, 2006; Kerstenetsky; 2000; Cerqueira e Lobão, 2004).

Os indicadores contextuais se referem a proxies de diferenciação dos municípios considerados. Foram selecionadas algumas dimensões de análise, relacionadas a variáveis específicas capazes de expressar diferenças em relação aos municípios do Estado. 0 Quadro 1 abaixo fornece as dimensões e suas respectivas variáveis.

Quadro 1 - Variáveis de caráter contextual, determinantes

\begin{tabular}{l} 
Variáveis contextuais - unidade de análise: município \\
\hline Contas públicas \\
\hline despesas por função - assistência e previdência - municipal \\
(2000) \\
despesas por função - habitação e urbanismo - municipal \\
(2000) \\
receita tributária - municipal (2000) \\
\hline Serviços públicos \\
\hline domicílios - com água encanada - pessoas (2000) \\
domicílios - com serviço de coleta de lixo - pessoas (2000) \\
domicílios - com energia elétrica - pessoas (2000) \\
domicílios - subnormais - pessoas (2000) \\
domicílios - com terreno próprio e quitado - pessoas (2000) \\
Taxa de Urbanização \\
\hline Renda e capacidades \\
\hline pobreza - pessoas pobres (p0) (2000) \\
percentual de pessoas com mais de 50\% da sua renda \\
proveniente de transferências \\
taxa de alfabetização, 2000 \\
\hline Condições de vida \\
Índice de desenvolvimento humano municipal, 2000 \\
Índice de gini, 2000 \\
Mortalidade até um ano de idade, 2000 \\
\hline \multicolumn{1}{c}{ Fonte: elaboração própria }
\end{tabular}

A primeira dimensão trazida à baila refere-se às Contas Públicas municipais. Seu objetivo é mensurar as despesas por função de cada cidade, tomando por base, especificamente, a assistência e previdência social e a habitação e urbanismo, bem como mensurar, também, a capacidade própria de arrecadação do governo local, através da receita tributária. Sugere-seque municípios com maior investimento em 


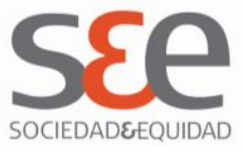

modernização administrativa e recursos seriam aqueles com maiores dispêndios e com maior capacidade de arrecadação própria.

A segunda dimensão de análise refere-se aos Serviços Públicos municipais. Neste caso, lidamos com o grau de acesso a bens e serviços públicos pelos domicílios e famílias locais. Tomamos por base elementos de base para garantia de bem-estar e saúde aos indivíduos, como acesso a água encanada e potável, coleta de lixo, energia elétrica, terreno próprio e urbanização. Sugere-se que a média de domicílios com acesso a tais serviços possa expressar a qualidade de sua oferta pelos governos municipais.

A terceira dimensão refere-se ao volume de renda e à capacidade dos indivíduos de efetivamente garantir renda própria. Neste caso, lidamos com variáveis como pobreza efetiva, o grau de alfabetização dos indivíduos (capaz de aumentar suas chances de conseguir emprego) e, por fim, sua dependência em relação à transferência de renda de programas sociais governamentais. A última dimensão é a de Condições de Vida e tenta mensurar de maneira efetiva quais as condições de moradia e bem-estar dos indivíduos do município. Para tanto, utilizamos os Índices IDH e Gini e um índice relacionado à mortalidade infantil, como forma de capturar os efeitos da falta de acesso a serviços de saúde e bens e serviços básicos, como saneamento e distribuição de remédios.

A análise AF para o caso das variáveis contextuais gerou, a partir dos quartis de prevalência de cada dimensão, combinações específicas de fatores. Os fatores foram classificados de acordo com os três critérios abaixo, com fins de facilitar a interpretação;

- BD - Baixo Déficit: significa que o município atingiu percentuais relativamente melhores nos indicadores analisados;

- MD - Médio Déficit: significa que o município atingiu percentuais medianamente significativos nos indicadores analisados;

- $A D$ - Alto Déficit: significa que os indicadores do município são relativamente piores comparativamente aos demais casos.

\section{Vulnerabilidade social e focalização de serviços}

Com base nas informações sobre mensuração e potencial de determinação do fenômeno da vulnerabilidade social, o procedimento seguinte do relatório consiste na junção de ambas as dimensões com vistas a gerar perfis latentes de municípios. Estes perfis conformarão a base dos prognósticos de determinação acerca de quais tipos de vulnerabilidades estariam ligadas em maior medida a determinados tipos de contextos. Com isso será possível não apenas informar quais seriam os tipos de vulnerabilidade 




presentes em cada município, mas, também, identificar aquelas mais prementes em termos de tratamento por parte dos gestores públicos para o caso de Minas Gerais.

Para realização desse procedimento, o método utilizado é GoM - Grade ofMembership, cuja descrição e explicação já foi feita na seção metodológica do trabalho, inclusive no que tange à adequação dos termos da equação para o objeto sendo tratado. 0 GoM gerou 4 perfis latentes de municípios, que se encontram expressos na Tabela 8. 0 Perfil 1 congrega basicamente vulnerabilidades ligadas muito mais aos públicos crianças (Fator 2 e 4), Adolescentes (Fator 1 e 4) e Famílias (Fator 1, 3 e 4). É interessante notar que, se considerarmos as variáveis de contexto, os municípios podem ser classificados com médio déficit no acesso a bens e serviços e na garantia de qualidade de vida aos habitantes. Isso é expresso, por exemplo, no caso do IDH, que chega até a 0,76 .

Tabela 8 - Perfis de vulnerabilidade municipais, Minas Gerais 2000

\begin{tabular}{|c|c|c|}
\hline Perfis & Características & $\%$ \\
\hline $\begin{array}{c}\text { Perfil } \\
1\end{array}$ & $\begin{array}{l}\text { Fator } 1 \text { adolescentes VSB } \\
\text { Fator } 2 \text { criancas - VSMB } \\
\text { Fator } 4 \text { Familia - VSMA } \\
\text { Fator } 1 \text { Familia - VSA } \\
\text { Fator } 4 \text { criancas - VMA } \\
\text { Fator } 3 \text { Familia - VSMB } \\
\text { Fator } 4 \text { adolescentes VSA } \\
\text { IDH-M até 0,76 } \\
\text { De } 38 \% \text { a 59\% de pobreza - pessoas pobres (p0) (2000) } \\
\text { Mais de 37\% de mortalidade até um ano de idade, 2000 } \\
\text { Até } 75 \% \text { de domicílios - com serviço de coleta de lixo - } \\
\text { pessoas (2000) } \\
\text { Até } 89 \% \text { domicílios - com energia elétrica - pessoas (2000) } \\
\text { Até } 77 \% \text { de taxa de alfabetização, } 2000 \\
\text { Até } 74 \% \text { domicílios - com água encanada - pessoas (2000) }\end{array}$ & 28,7 \\
\hline $\begin{array}{c}\text { Perfil } \\
2\end{array}$ & $\begin{array}{l}\text { Fator } 1 \text { Familia - VSA } \\
\text { Fator } 4 \text { PPD - VSMB } \\
\text { Fator } 1 \text { idosos VSB } \\
\text { Fator } 1 \text { criancas - VSB } \\
\text { Fator } 3 \text { idosos - VSA } \\
\text { IDH-M acima de } 0,729 \\
\text { Até } 58 \% \text { de pobreza - pessoas pobres (p0) (2000) } \\
\text { Mais de } 95 \% \text { de domicílios - com água encanada - pessoas }\end{array}$ & 27,4 \\
\hline
\end{tabular}




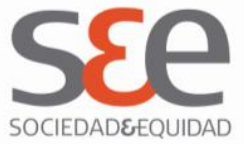

\begin{tabular}{|c|c|c|}
\hline & $\begin{array}{l}\text { Mais de } 96 \% \text { de domicílios - com serviço de coleta de lixo - } \\
\text { pessoas }(2000) \\
\text { Mais de } 98 \% \text { de domicílios - com energia elétrica - pessoas } \\
(2000) \\
\text { Até } 11 \% \text { de pessoas com mais de } 50 \% \text { da sua renda } \\
\text { proveniente de transferencias }\end{array}$ & \\
\hline $\begin{array}{c}\text { Perfil } \\
3\end{array}$ & $\begin{array}{l}\text { Fator } 2 \text { Familia - Fator VSA } \\
\text { Fator } 1 \text { idosos - VSB } \\
\text { Fator } 3 \text { criancas - VSA } \\
\text { Fator } 3 \text { adolescentes VSMA } \\
\text { Fator } 2 \text { PPD - VSB } \\
\text { Fator } 3 \text { PPD - VSMA } \\
\text { Mais de } 11,5 \% \text { de despesas por função - habitação e } \\
\text { urbanismo - municipal (2000) } \\
\text { Mais de } 6,2 \% \text { de receita tributária - municipal (2000) } \\
\text { Mais de } 98,7 \% \text { de domicílios - com energia elétrica - } \\
\text { pessoas (2000) } \\
\text { Mais de } 79 \% \text { de Taxa de Urbanização } \\
\text { Mais de } 87,9 \% \text { de taxa de alfabetização, } 2000\end{array}$ & 20,4 \\
\hline $\begin{array}{c}\text { Perfil } \\
4\end{array}$ & $\begin{array}{l}\text { Fator } 3 \text { Familia - VSMB } \\
\text { Fator } 3 \text { idosos VSM } \\
\text { Fator } 2 \text { criancas - VSMB } \\
\text { Fator } 2 \text { adolescentes - VSMB } \\
\text { Fator } 4 \text { Familia - VSMA } \\
\text { Até } 74 \% \text { de domicílios - com água encanada - pessoas } \\
\text { (2000) } \\
\text { Mais de 58\% de pobreza - pessoas pobres (p0) (2000) } \\
\text { Até } 89 \% \text { de domicílios - com energia elétrica - pessoas } \\
\text { (2000) } \\
\text { Até } 1,45 \% \text { de receita tributária - municipal (2000) } \\
\text { Até } 63,6 \% \text { de Taxa de Urbanização }\end{array}$ & 23,4 \\
\hline & TOTAL & 100 \\
\hline
\end{tabular}

Fonte: IBGE, Censo 2000 




O Perfil 2 congrega municípios com tipos de vulnerabilidade mais variados. Temos, neste caso, os públicos Famílias (Fator 1), Idosos (Fator 1 e 3), Crianças (Fator 1) e, por fim, PPD (Fator 4). O perfil contextual, em termos de variáveis dessa natureza, concerne a locais com déficit baixo no que tange à oferta de bens e serviços e garantia de bem-estar à população. A média de IDH, por exemplo, situa-se acima de 0,73 e, além disso, o percentual de pessoas pobres situa-se abaixo de $58 \%$. Mais de $98 \%$ dos domicílios têm energia elétrica, água encanada e serviço de coleta de lixo.

Quando consideramos o Perfil 3, percebemos maior concentração do tipo de vulnerabilidade do público PPD. Temos os seguintes públicos: Adolescentes (Fator 3), Crianças (Fator3), Famílias (Fator 2) e, por fim, PPD (Fator 2 e 3). Estes domicílios podem ser considerados também contendo baixo déficit em termos de oferta de serviços e bens públicos, dado que, por exemplo, o percentual de domicílios com energia elétrica ultrapassa os $98 \%$, assim como a taxa de urbanização é significativa, atingindo mais de 79\%. O município conta, também, com uma arrecadação tributária própria de 6,2\%, o que demonstra capacidade administrativo-tributária de arregimentar um sistema próprio de coleta de tributos.

O último Perfil, de número 4, congrega os públicos Família, Crianças, Adolescentes e Idosos, mas tomando por base outros tipos de fatores gerados. No caso do público Famílias, temos os fatores 3 e 4; no caso do público crianças, o fator 2; para o público adolescentes, o fator 2; e, por fim, para o público idosos, o fator 2 . As características contextuais destes municípios podem ser dadas como de alto déficit em termos de acesso a bens e serviços públicos. São locais com mais de $58 \%$ de domicílios pobres. Menos de $74 \%$ tem acesso a água encanada, a taxa de urbanização fica abaixo de $63,6 \%$ e, por fim, a receita tributária é relativamente baixa, de apenas 1,45\%, demonstrando baixa modernização administrativa e capacidade de arrecadação própria.

A distribuição dos municípios, segundo cada perfil latente gerado pelo GoM, parece refletir constatações de estudos anteriores acerca da distribuição de riqueza no Estado de Minas Gerais. O Mapa 10 mostra essa distribuição. O que podemos notar, em primeiro lugar, é que, considerando os município do Perfil 4, considerados, como visto, de alto déficit no acesso a bens e serviços públicos e com vulnerabilidades identificadas para os públicos crianças, adolescentes e famílias, constata-se concentração nas regiões Norte e Nordeste do Estado. Isso conforma perspectiva de que essas regiões conformam as mais pobres do Estado, com o adendo de que a priorização de investimentos e planejamento s públicos deve ser realizada com base nos públicos identificados como vulneráveis nestes locais. 


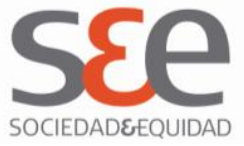

Mapa 6 - Distribuição dos perfis de vulnerabilidade municipais, Minas Gerais 2000

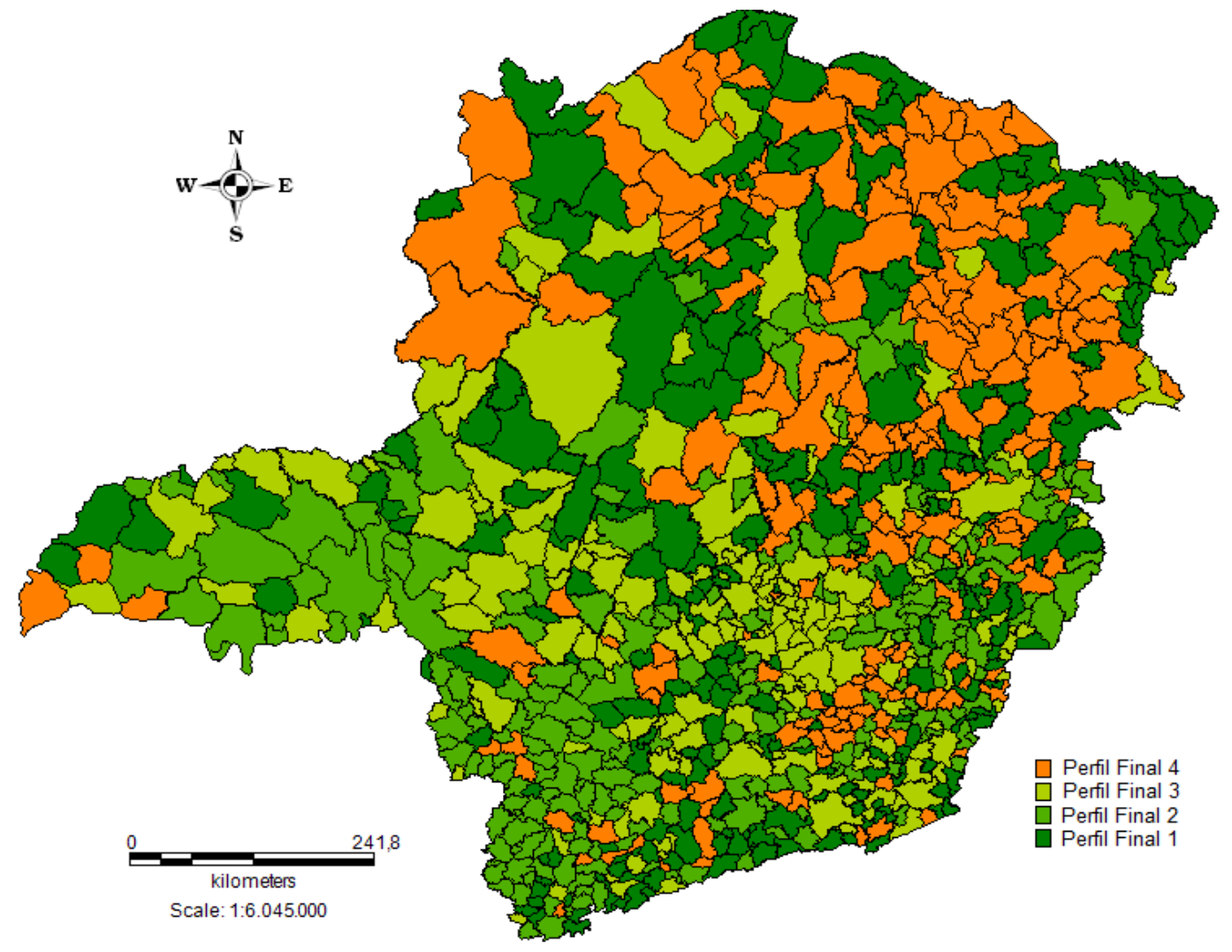

Fonte: IBGE, Censo 2000

Quando levamos em consideração os perfis 2 e 3, com baixo déficit de acesso a bens e serviços públicos e com públicos vulneráveis identificados como idosos, crianças e adolescentes, famílias e PPD, não é difícil notar que sua distribuição é significativa ao longo do território. As concentrações se dão nas regiões Central e Sul de Minas de uma maneira geral. Nestes casos, os públicos identificados linhas acima devem ser prioridade nos investimentos em políticas e planejamento pelos governos locais. 0 último perfil, o Perfil 4, concerne a municípios com alto déficit social em termos de acesso a bens e serviços públicos, bem como com vulnerabilidades sociais relativamente severas dos públicos crianças, adolescentes, famílias e idosos. Sua distribuição territorial abrange o Norte e Nordeste do Estado e algumas outras poucas cidades de outras regiões, distribuindo-se de maneira semelhante às cidades identificadas no Perfil 1. 




\section{Modelo preditivo de Vulnerabilidade Social}

O trabalho até agora desenvolvido permitiu gerar perfis de vulnerabilidade dos municípios de Minas Gerais e classifica-los segundo aqueles tipos mais prementes de priorização no âmbito do planejamento e gestão de políticas públicas. A partir dessas informações, seria interessante gerar uma função preditiva que, baseada nas características dos municípios, expressas aqui sob a forma das variáveis de contexto trazidas à baila, fosse capaz de mensurar a propensão de determinado município de enfrentar determinados tipos de vulnerabilidades sociais. Dito de outra forma, dadas certas características dos municípios, qual o tipo mais provável de vulnerabilidade dado município estará prementemente sujeito, medianamente sujeito e, por fim, com baixo potencial de a ela estar sujeito?

Esta seção final do relatório lida exatamente com esta questão e aplica o modelo de regressão logística multinomial descrito na seção metodológica do trabalho. 0 primeiro passo consiste na clarificação da variável de interesse. Sua composição se dará pelo que denominamos aqui de "Perfis compostos de vulnerabilidade", doravante PCVs. Os PCVs consistem nos perfis gerados pelo método GoM, retirando-se, de cada perfil, as variáveis referentes ao contexto externo dos municípios e mantendo, para fins analíticos, os fatores de vulnerabilidades relacionados a cada público-alvo considerado. Nessa linha, temos, ao final, 4 perfis compostos de vulnerabilidade, tal como mostrado no Tabela 9. A composição final da variável de interesse, assim, se dá considerando cada perfil como uma categoria de análise, justificando, portanto, a utilização da técnica multinomial de regressão logística.

Tabela 9 - Perfis de vulnerabilidade para composição do modelo preditivo final, Minas Gerais 2000

\begin{tabular}{rl|c}
\hline Fator & \multicolumn{1}{c|}{ Características } & $\%$ \\
\hline & Fator 1 Familia - VSA & \\
& Fator 4 criancas - & \multirow{2}{*}{28,7} \\
Fator 1 & VMA \\
& Fator 4 adolescentes & \\
& VSA & \\
\hline Fator 2 & Fator 1 Familia - VSA & \\
& Fator 4 PPD - VSMB & 27,4 \\
& Fator 3 idosos - VSA & \\
& VSA criancas - & \\
Fator 3 & Fator 3 adolescentes & 20,5 \\
& VSMA \\
& Fator 3 PPD - VSMA &
\end{tabular}






Fonte: IBGE, Censo 2000

Quando considerarmos as variáveis independentes, optou-se, com fins de melhorar e facilitar a interpretação dos dados e do próprio modelo, tomar por base os fatores gerados em cada dimensão analítica de cunho contextual. Como já demonstrado linhas acima, as variáveis determinantes de vulnerabilidade foram consideradas com base em 4 dimensões, sendo, Contas Públicas, Serviços Públicos, Renda e Capacidades e, por fim, Condições de Vida. Estas dimensões foram construídas tendo por base as variáveis e fatores latentes gerados tal como visto no Quadro 1. Para a estruturação do modelo de regressão, iremos utilizar exatamente aquela classificação, que relacionou 3 perfis de prevalência para cada dimensão: Alta Deficiência, Média Deficiência e Baixa Deficiência. A Tabela 10 traz o cruzamento da variável dependente e das variáveis independentes, tal como descritas.

Tabela 10 - Cruzamento variáveis dependentes e independentes para o modelo preditivo de Vulnerabilidades municipais, Minas Gerais 2000

\begin{tabular}{|c|c|c|c|c|c|c|}
\hline & \multirow[t]{2}{*}{ Deficiência } & \multicolumn{4}{|c|}{$\begin{array}{l}\text { Perfis Compostos de } \\
\text { Vulnerabilidade }\end{array}$} & \multirow[t]{2}{*}{ Total } \\
\hline & & Perfil 1 & Perfil 2 & Perfil 3 & Perfil 4 & \\
\hline \multirow{3}{*}{$\begin{array}{l}\text { Contas } \\
\text { Públicas }\end{array}$} & Baixa & $37,3 \%$ & $14,7 \%$ & $26,0 \%$ & $22,1 \%$ & $100,0 \%$ \\
\hline & Média & $25,7 \%$ & $19,6 \%$ & $30,9 \%$ & $23,9 \%$ & $100,0 \%$ \\
\hline & Alta & $26,1 \%$ & $23,6 \%$ & $27,3 \%$ & $23,0 \%$ & $100,0 \%$ \\
\hline \multirow{3}{*}{$\begin{array}{l}\text { Serviços } \\
\text { Públicos }\end{array}$} & Baixa & $20,9 \%$ & $24,2 \%$ & $26,9 \%$ & $27,9 \%$ & $100,0 \%$ \\
\hline & Média & $27,6 \%$ & $20,5 \%$ & $28,3 \%$ & $23,6 \%$ & $100,0 \%$ \\
\hline & Alta & $38,6 \%$ & $14,3 \%$ & $30,1 \%$ & $17,0 \%$ & $100,0 \%$ \\
\hline \multirow{3}{*}{$\begin{array}{c}\text { Renda e } \\
\text { Capacidades }\end{array}$} & Baixa & $29,4 \%$ & $19,6 \%$ & $28,0 \%$ & $23,0 \%$ & $100,0 \%$ \\
\hline & Média & $22,5 \%$ & $26,3 \%$ & $24,3 \%$ & $26,9 \%$ & $100,0 \%$ \\
\hline & Alta & $37,2 \%$ & $10,2 \%$ & $35,3 \%$ & $17,2 \%$ & $100,0 \%$ \\
\hline \multirow{3}{*}{$\begin{array}{l}\text { Condições } \\
\text { de Vida }\end{array}$} & Baixa & $30,6 \%$ & $18,5 \%$ & $32,8 \%$ & $18,1 \%$ & $100,0 \%$ \\
\hline & Média & $27,4 \%$ & $23,6 \%$ & $24,2 \%$ & $24,8 \%$ & $100,0 \%$ \\
\hline & Alta & $28,0 \%$ & $16,5 \%$ & $29,2 \%$ & $26,3 \%$ & $100,0 \%$ \\
\hline
\end{tabular}

Fonte: IBGE, Censo 2000 


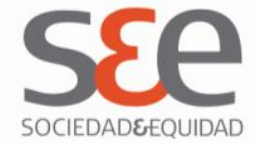

Com base no cruzamento das variáveis dependente e independentes, estimou-se alguns modelos de regressão logística multinomial com fins de verificar quais fatores teriam influência na propensão ao desenvolvimento de tipos específicos de vulnerabilidade pelos municípios. Estes modelos contaram, cada qual, com um conjunto específico de dimensões de variáveis independentes, sendo construídos, nesse sentido, de maneira progressiva. 0 primeiro modelo contou com apenas uma dimensão, referente às categorias de prevalência de Contas Públicas dos municípios. O segundo modelo incluiu a dimensão referente aos Serviços Públicos prestados localmente, também com base em suas categorias de prevalência. O terceiro modelo contou com a adição da dimensão referente à Renda e Capacidade dos domicílios. Por fim, o último modelo levou em consideração, também, a dimensão relativa às Condições de Vida dos domicílios. A Tabela 11 mostra os modelos de regressão criados, apresentando, para cada qual, as respectivas razões de chance, coeficiente de erro padrão e coeficiente de significância estatística.

Tabela 11 - Modelos preditivos de vulnerabilidade municipal, Minas Gerais 2000

\begin{tabular}{|c|c|c|c|c|c|c|c|}
\hline \multirow[t]{2}{*}{ Dimensão } & \multirow{2}{*}{$\begin{array}{c}\text { Deficiênci } \\
\text { a }\end{array}$} & \multicolumn{3}{|c|}{$\begin{array}{c}\text { Modelo } 1 \\
\text { Perfil de Vulnerabilidade }\end{array}$} & \multicolumn{3}{|c|}{$\begin{array}{c}\text { Modelo } 2 \\
\text { Perfil de Vulnerabilidade }\end{array}$} \\
\hline & & 2 & 3 & 4 & 2 & 3 & 4 \\
\hline \multirow{5}{*}{$\begin{array}{l}\text { Contas } \\
\text { Públicas }\end{array}$} & Baixa & Ref. & Ref. & Ref. & Ref. & Ref. & Ref. \\
\hline & \multirow{2}{*}{ Média } & $0.658^{* *}$ & $0.545^{* *}$ & $0.450^{*}$ & $0.572^{* *}$ & $0.508^{* *}$ & 0.362 \\
\hline & & $(0.272)$ & $(0.232)$ & $(0.245)$ & $(0.275)$ & $(0.233)$ & $(0.249)$ \\
\hline & \multirow{2}{*}{ Alta } & $0.829^{* * *}$ & $0.407^{*}$ & 0.397 & $0.665^{* *}$ & 0.334 & 0.229 \\
\hline & & $(0.267)$ & $(0.235)$ & $(0.247)$ & $(0.273)$ & $(0.239)$ & $(0.252)$ \\
\hline \multirow{5}{*}{$\begin{array}{l}\text { Serviços } \\
\text { Públicos }\end{array}$} & Baixa & Ref. & Ref. & Ref. & Ref. & Ref. & Ref. \\
\hline & \multirow{2}{*}{ Média } & & & & $-0.425^{*}$ & -0.216 & $-0.439^{*}$ \\
\hline & & & & & $(0.243)$ & $(0.230)$ & $(0.234)$ \\
\hline & \multirow{2}{*}{ Alta } & & & & $-1.053^{* * *}$ & $-0.460^{* *}$ & $-1.082^{* * *}$ \\
\hline & & & & & $(0.262)$ & $(0.230)$ & $(0.250)$ \\
\hline \multirow{2}{*}{\multicolumn{2}{|c|}{$\begin{array}{c}\text { \# de obs. } \\
\mathrm{R}^{2} \text { ajustado }\end{array}$}} & 853 & 853 & 853 & 853 & 853 & 853 \\
\hline & & 0.0563 & 0.0563 & 0.0563 & 0.169 & 0.169 & 0.169 \\
\hline \multirow{3}{*}{ Dimensão } & \multirow{3}{*}{$\begin{array}{c}\text { Deficiênci } \\
\text { a }\end{array}$} & \multicolumn{3}{|c|}{ Modelo 3} & \multirow{2}{*}{\multicolumn{3}{|c|}{$\begin{array}{c}\text { Modelo } 4 \\
\text { Perfil de Vulnerabilidade }\end{array}$}} \\
\hline & & \multicolumn{3}{|c|}{ Perfil de Vulnerabilidade } & & & \\
\hline & & 2 & 3 & 4 & \multicolumn{3}{|c|}{\begin{tabular}{c|c|c} 
& Perfil de Vulnerabilidade \\
2 & 3 & 4
\end{tabular}} \\
\hline Contas & Baixa & Ref. & Ref. & Ref. & Ref. & Ref. & Ref. \\
\hline
\end{tabular}




\begin{tabular}{|c|c|c|c|c|c|c|c|}
\hline \multirow[t]{3}{*}{ Públicas } & Média & $\begin{array}{l}0.489^{*} \\
(0.279)\end{array}$ & $\begin{array}{l}0.527^{* *} \\
(0.235)\end{array}$ & $\begin{array}{c}0.317 \\
(0.251)\end{array}$ & $\begin{array}{l}0.470^{*} \\
(0.280)\end{array}$ & $\begin{array}{l}0.521^{* *} \\
(0.236)\end{array}$ & $\begin{array}{c}0.337 \\
(0.252)\end{array}$ \\
\hline & \multirow{2}{*}{ Alta } & $0.512^{*}$ & 0.355 & $0.139^{*}$ & $0.491^{*}$ & $0.344^{*}$ & 0.166 \\
\hline & & $(0.278)$ & $(0.242)$ & $(0.257)$ & $(0.279)$ & $(0.243)$ & $(0.258)$ \\
\hline \multirow{5}{*}{$\begin{array}{l}\text { Serviços } \\
\text { Públicos }\end{array}$} & Baixa & Ref. & Ref. & Ref. & Ref. & Ref. & Ref. \\
\hline & \multirow{2}{*}{ Média } & -0.399 & -0.206 & $-0.421^{*}$ & $-0.372^{*}$ & $-0.217^{* * *}$ & $-0.423^{*}$ \\
\hline & & $(0.245)$ & $(0.231)$ & $(0.235)$ & $(0.246)$ & $(0.231)$ & $(0.236)$ \\
\hline & \multirow{2}{*}{ Alta } & $-0.749^{* * *}$ & $-0.511^{* *}$ & $-0.906^{* * *}$ & $-0.758^{* * *}$ & $-0.541^{* *}$ & $-0.868^{* * *}$ \\
\hline & & $(0.277)$ & $(0.244)$ & $(0.264)$ & $(0.279)$ & $(0.248)$ & $(0.265)$ \\
\hline \multirow{5}{*}{$\begin{array}{c}\text { Renda e } \\
\text { Capacidad } \\
\text { es }\end{array}$} & Baixa & Ref. & Ref. & Ref. & Ref. & Ref. & Ref. \\
\hline & \multirow{2}{*}{ Média } & $0.479^{* *}$ & $0.0823^{*}$ & 0.361 & $0.467^{* *}$ & 0.0557 & $0.399^{*}$ \\
\hline & & $(0.234)$ & $(0.223)$ & $(0.227)$ & $(0.237)$ & $(0.226)$ & $(0.230)$ \\
\hline & \multirow{2}{*}{ Alta } & $-0.617^{* *}$ & 0.209 & $-0.249^{* *}$ & $-0.617^{*}$ & 0.146 & $-0.178^{* *}$ \\
\hline & & $(0.311)$ & $(0.240)$ & $(0.275)$ & $(0.322)$ & $(0.250)$ & $(0.283)$ \\
\hline \multirow{5}{*}{$\begin{array}{l}\text { Condições } \\
\text { de Vida }\end{array}$} & Baixa & Ref. & Ref. & Ref. & Ref. & Ref. & Ref. \\
\hline & \multirow{2}{*}{ Média } & & & & $0.105^{*}$ & $-0.264^{* *}$ & 0.227 \\
\hline & & & & & $(0.252)$ & $(0.229)$ & $(0.249)$ \\
\hline & \multirow{2}{*}{ Alta } & & & & $-0.235^{* *}$ & $-0.0979^{* *}$ & $0.285^{*}$ \\
\hline & & & & & $(0.286)$ & $(0.245)$ & $(0.268)$ \\
\hline \multicolumn{2}{|c|}{ \# de obs. } & 853 & 853 & 853 & 853 & 853 & 853 \\
\hline
\end{tabular}

${ }^{*}$ Sig a 0,$1 ;{ }^{* *}$ Sig a 0,$05 ;{ }^{* *}$ Sig a 0,001

Obs: considerando como categorias de referência "Baixa” para Contas Públicas; "Baixa" para Serviços Públicos; "Baixa” para Renda e Capacidades; "Baixa” para Condições de vida; e, por fim, "Perfil de Vulnerabilidade 1" para a variável Dependente Perfis de Vulnerabilidade, a equação de regressão foi montada da seguinte forma: $[P / 1-P]=B_{0}+$ $B_{1}$ (Média deficiência em Contas Públicas) + $B_{2}$ (Alta deficiência em Contas Públicas) + $B_{3}$ (Média deficiência em Serviços Públicos) $+B_{4}$ (Alta deficiência em Serviços Públicos) + $B_{5}$ (Média deficiência em Renda e Capacidades) $+B_{6}$ (Alta deficiência em Renda $e$ Capacidades) $+B_{7}$ (Média deficiência em Condições de Vida) $+B_{8}$ (Alta deficiência em Condições de vida) $+U_{i}$.

Fonte: IBGE, Censo 2000 


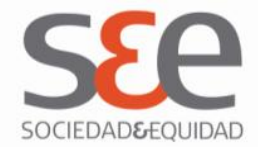

O modelo 1 sugere que municípios com Contas Públicas caracterizadas por graus médio e alto de deficiência têm, no geral, razões de chance maiores, ou, em outras palavras, maior propensão relativa, de incorrer em vulnerabilidades dos tipos 2, 3 e 4, respectivamente, quando comparados com municípios caracterizados por baixa deficiência nesse quesito e contando com vulnerabilidade de perfil 1, isto é, alta vulnerabilidade crianças, adolescentes e famílias. Se considerarmos, por exemplo, o critério de Alta deficiência em Contas Públicas, notamos que a probabilidade municipal de incorrer em vulnerabilidade de perfil 2, que indica a priorização dos públicos Famílias, Idosos e PPD, aumenta em 0,8 vezes e em 0,4 vezes quando consideramos 0 perfil 3, relativo à priorização dos públicos crianças, adolescentes e PPD.

Nessa mesma linha, quando consideramos o critério de Média Deficiência em Contas Públicas, há tendência semelhante. À medida que modificamos o tipo de priorização, parece haver clara correlação com a dimensão externa. Há uma razão de chance 0,6 vezes maior de priorizar, por exemplo, os públicos Famílias, PPD e Idosos ao invés do trio Família, Crianças e Adolescentes, quando há uma média deficiência em Contas Públicas. Razão de chance que varia para 0,5 quando consideramos o perfil 3 , que indica priorização dos públicos Crianças, adolescentes e PPD e 0,45 quando consideramos os perfil 4, que indica priorização dos públicos Famílias e Idosos, somente.

Estes dados são interessantes porque indicam relação de causalidade entre o controle financeiro municipal e os reflexos nos tipos de vulnerabilidades a que estarão sujeitos os indivíduos locais. Quanto maior a deficiência em Contas Públicas, observa-se uma diversificação dos públicos afetados, já que, em situações de Baixa deficiência, temos a predominância dos públicos Famílias, crianças e adolescentes e, à medida que avançamos nos graus de deficiência, observamos a inclusão e diferenciadas combinações de públicos como Idosos, PPD em severidades diferenciadas.

O modelo 2 da regressão inclui outra dimensão analítica, que é a de Serviços Públicos. Neste caso, observamos um aumento do coeficiente de correlação ajustado, de $5 \%$ para quase $17 \%$, indicando o significativo peso da dimensão. Além disso, nota-se que ainda é estatisticamente significante as correlações encontradas para a primeira dimensão analisada, de Contas Públicas, o que quer dizer que as análises correlatas são consistentes. Quando analisamos a dimensão de Serviços Públicos, notamos, todavia, tendências ligeiramente diferenciadas em relação a Contas Públicas. Parece que, neste caso, a diminuição das deficiências é que tende a provocar diversificação de públicos e respectivos graus de vulnerabilidade e não o contrário.

Se analisarmos, por exemplo, o aspecto de Alta deficiência em Serviços Públicos, notamos que há uma razão de chance de menos 1,05 vezes do município incorrer em Vulnerabilidade de perfil 2, que prioriza os públicos Famílias, PPD e Idosos, do que a do perfil 1, que prioriza Famílias, Crianças e Adolescentes. Isso quer dizer que em 




municípios com alta deficiência em Serviços Públicos é muito mais provável encontrarmos vulnerabilidades nos públicos Crianças e Adolescentes do que nos públicos Idosos e PPD, sugerindo fortemente que crianças e adolescentes são mais impactadas por falta de serviços públicos do que idosos e PPDs.

Essa mesma linha analítica mostra-se consistente para os demais graus de severidade de deficiência e vulnerabilidades. Quando consideramos, por exemplo, municípios de média deficiência em Serviços Públicos, notamos diminuição em média de 0,4 vezes as chances de desenvolvimento de vulnerabilidades dos tipos 2 , 3 e 4 em relação a municípios com vulnerabilidade tipo 1 e com baixa deficiência no quesito. Isso quer dizer que, efetivamente, o aumento nas deficiências em serviços públicos não tem o mesmo efeito de diversificação de públicos que foi observado para o caso da dimensão de Contas Públicas. Na perspectiva do gestor, esse pode se revelar um dado interessante, já que há evidências de que suas ações em políticas públicas de acesso a bens e serviços tenderão a surtir maior influência na situação de Famílias, crianças e adolescentes do que na situação do grupo de Famílias, Idosos e PPDs, por exemplo.

O terceiro modelo estimado com base nos dados considerou inclusão da dimensão de Renda e Capacidades. Observamos, neste caso, um incremento também notável do coeficiente de correlação ajustado, passando de $17 \%$ para quase $27 \%$, o que indica que a dimensão é significativa do ponto de vista da análise. Além disso, observamos, também, que as dimensões anteriores mantiveram significância estatística nos quesitos trabalhados, assim como as tendências apontadas de suas respectivas razões de chances, o que sugere que as análises correlatas se mantêm consistentes neste modelo. Ao observamos a dimensão em pauta, de Renda e Capacidade, não obstante, notamos tendências mistas se comparada com os dois casos anteriores. Parece que há diversificação de públicos e tipos de vulnerabilidades até certo grau de deficiência no quesito e tendência a maior homogeneização para graus altos na escala.

Se considerarmos os municípios com grau médio de deficiência para Renda e Capacidades, notamos incremento das razões de chance para desenvolvimento de vulnerabilidades dos tipos 2, 3 e 4 em relação a municípios com baixo grau de deficiência neste quesito e imbuídos em vulnerabilidades de perfil 1. Há uma chance 0,5 vezes maior de desenvolvimento de vulnerabilidade tipo 2, por exemplo, quando o município tem grau médio e não baixo de deficiência em Renda e Capacidades. Nesse mesmo sentido, essa razão é também maior para o desenvolvimento de vulnerabilidades de tipo 3, sendo aproximadamente 0,1 . Essa tendência revela evidências claras de o aumento de deficiência dos municípios de baixo para médio em Renda e Capacidades irá provocar uma diversificação dos públicos e tipos de vulnerabilidades às quais estarão sujeitos. 


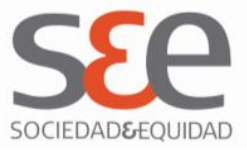

No outro extremo, quando consideramos a faixa de alta deficiência na dimensão de Renda e Capacidades, observamos movimento inverso. Há, por exemplo, uma chance 0,6 vezes menor de um município nessa situação incorrer em vulnerabilidades do tipo 2 , que diversifica os públicos e prioriza Idosos e PPDs, em relação a municípios com baixa deficiência no quesito e com vulnerabilidades de perfil 1, centradas em Famílias, crianças e adolescentes. Nessa mesma linha, essa razão de chance é de 0,25 vezes menor quando consideramos o desenvolvimento de vulnerabilidades de perfil 4, que também diversifica os públicos, considerando, no seu caso, Famílias e Idosos com média severidade. 0 que esses dados evidenciam, enfim, é que municípios que desenvolvem alta deficiência em Renda e Capacidades terão afetados muito mais os públicos crianças e adolescentes, do que públicos outros diversos, como Idosos e PPDs. Isso quer dizer que, em adição aos Serviços Públicos, maior deficiência em Renda e Capacidades também influencia sobremaneira, relativamente, a situação de Famílias, crianças a adolescentes nos municípios brasileiros.

O último modelo considerado na análise faz agregação da dimensão de Condições de Vida. Neste caso, observamos também um aumento do coeficiente de correlação R2 ajustado, que passa de $27 \%$ para $30 \%$. Além disso, é possível notar que a significância estatística dos vetores das três dimensões anteriores é mantida, bem como os sentidos observados dos scores de razões de chance, o que permite afirmar que todas as tendências apresentadas se mantêm constante nesse modelo final. Levando em consideração a dimensão de Condições de Vida, há tendência ainda mais mesclada se comparada com as anteriores. Parece que, neste caso, o aumento da deficiência aumenta a probabilidade de desenvolvimento de vulnerabilidades a públicos diversificados até certo tipo de público.

Se considerarmos, por exemplo, os municípios com alto grau de deficiência em Condições de Vida, notamos chance 0,23 menor de encontrarmos públicos mais diversos relativos aos perfis de vulnerabilidade 2 e 3 , referentes, respectivamente, às combinação Famílias, Idosos e PPDs e Crianças, adolescentes e PPDs. No caso do perfil 4, as chances são inversas, sendo de 0,285 maior a probabilidade de encontrarmos este perfil. Como este último não tem em sua composição o público PPD, há evidências suficientes para afirmar que municípios com alta deficiência em Condições de Vida estarão mais propensos a desenvolver vulnerabilidades para o público PPD do que municípios com baixa deficiência nesse quesito, o que quer dizer que esse alto grau de deficiência para afetar muito mais este público do que os demais.

Lidando com os municípios de médio grau de deficiência em Condições de Vida, encontramos tendência ligeiramente diferenciada. Neste caso, há um incremento de 0,1 vezes nas chances de diversificação de públicos de perfil 1 de vulnerabilidade, que indica priorização de Famílias, Idosos e PPDs, mas, a seu turno, há uma chance 0,26 vezes menor de probabilidade de desenvolvimento de vulnerabilidade perfil 2 , cuja qual 


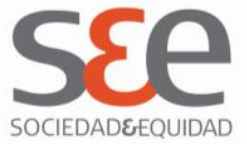

não considera o público Famílias em seus meandros. Isso sugere que, no caso dos municípios de média deficiência em Condições de Vida, o público Famílias tende a sofrer maiores efeitos dessa deficiência, em comparação com municípios de baixa deficiência e caracterizados pelo perfil 1 de vulnerabilidade.

\section{Considerações Finais}

Este trabalho procurou estudar a relação entre perfis de vulnerabilidade social e a influência dos contextos de inserção de dados públicos da assistência na probabilidade média de incursão em alguns destes perfis. A principal hipótese pesquisa foi de que os indivíduos estão sujeito a tipos determinados de vulnerabilidades sociais a guisa do seu local de vivência e inserção social, dada própria vulnerabilidade ser um fenômeno multidimensional e multicausado. Neste sentido, ela não estaria relacionada tão somente à falta de condições financeiras para sobrevivência, mas contaria, também, com um componente de efetivação em rede capaz de perpetuá-la e reproduzi-la no espaço e no tempo.

Em primeiro lugar, os dados evidenciaram ligação entre maior deficiência no quesito de Contas Públicas e diversificação dos públicos sujeitos a graus variados de vulnerabilidades. Essa constatação é interessante porque sugere ligação entre capacidade e também qualidade dos investimentos realizados pelo município em programas e políticas sociais. O segundo ponto a ser considerado é de que municípios com maior deficiência em Serviços Públicos tendem a gerar maior vulnerabilidade para públicos específicos, como crianças e adolescentes, mas não para públicos mais diversos, como idosos e PPDs. Isso sugere que a quantidade e a qualidade da oferta de serviços públicos tende a afetar muito mais os públicos crianças e adolescentes do que públicos como os últimos citados. Afirmação essa que é interessante do ponto de vista do planejamento de políticas para estes últimos, já que se supõe, neste sentido, que não necessariamente o aumento da oferta de serviços públicos irá gerar efeitos positivos no tratamento de suas vulnerabilidades. O terceiro ponto a considerar se refere à dimensão Renda e Capacidades. Neste caso, foi interessante perceber que um médio grau de diversificação desse quesito levou a uma diversificação de tipos de vulnerabilidades presentes, como idosos e PPDs, ao passo que um alto grau de deficiência teve efeito contrário, isto é, manteve as vulnerabilidades nas categorias de referência crianças e adolescentes. O interessante nesse dado é saber que, mesmo dentre uma única dimensão, há variações de intensidade e severidade de deficiências que podem fazer diferença na propensão média a que o município enfrente ou incorra em determinados tipos de vulnerabilidades. 


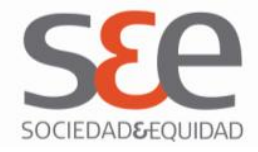

\section{Referencias Bibliograficas}

Andrade, M. V. E. e Lisboa, M. B. (2000). Desesperança de Vida: Homicídio em Minas Gerais, Rio de Janeiro e São Paulo - 1981 a 1997. In: R. Henriques (org.), Desigualdade e Pobreza no Brasil. Rio de Janeiro, IPEA.

Beato, C. C. e Reis, I. A. (2000). Desigualdade, Desenvolvimento Socioeconômico e Crime. In:R. Henriques (org.), Desigualdade e Pobreza no Brasil. Rio de Janeiro, IPEA.

Cano, I. e Soares, G. D. (2002). As Teorias sobre as Causas da Criminalidade. Rio de Janeiro, IPEA, Manuscrito.

Carneiro, C. B. L. (2005). Concepções sobre pobreza e alguns desafios para a intervenção social. Serviço Social e Sociedade. São Paulo, V. 84, p 66-90.

Castro, M. G; Abramovay, M. (2002). Jovens em situação de pobreza. Cadernos de Pesquisa, no 116, p. 143-176, julho.

Cavalcanti, M. M. A. (2006). Avaliação de Políticas Públicas e Programas Governamentais - Uma abordagem conceitual. www.interfacesdesaberes.fafica.com/seer/. 20hs/16/10/2006.

Cerqueira, D. R. C. e Lobao, W. A. J. L. (2003). Condicionantes Sociais, Poder de Polícia e o Setor de Produção Criminal. Texto para Discussão, nº 957, IPEA.

Criminalidade: Arcabouços Teóricos e Resultados Empíricos. DADOS - Revista de Ciências Sociais, Rio de Janeiro, Vol. 47, no 2, pp. 233 a 269.

Draibe, S. (2001). "Introdução”, em: Barreira, M.C. e Carvalho, M. Tendências e perspectivas na avaliação de políticas e programas sociais. São Paulo: IEE/PUC-SP, pp. 15 - 42.

Farah, Marta F. S. (2004). Gênero e políticas públicas. Revistas de Estudos Feministas, Florianópolis, V. 12, n.1. Disponível em: <http://www.scielo.br>. Acesso em: 12.12.2006.

Hair, J.F; Anderson, R.E; Tatham, R.L.; Black, W.C. (2005). Análise Multivariada de Dados. $5^{\circ}$ ed. Porto Alegre: Boockman.

Kerstenetsky, C. (2000) Desigualdade e pobreza: lições de Sen.Revista Brasileira de Ciências Sociais, São Paulo, v. 15, n. 42. Disponível em: <http://www.scielo.br.> Acesso em: 01 Nov 2006. 


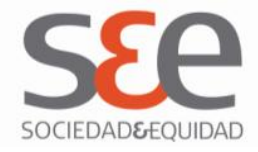

Lavinas, L. e Nicoll, M. (2006). Atividade e Vulnerabilidade: Quais os Arranjos Familiares em Risco? DADOS - Revista de Ciências Sociais, Rio de Janeiro, Vol. 49, no 1, 2006, pp. 67 a 97.

Pires, R.; Vaz, A.C. N. (2010). Participação faz diferença? Uma avaliação das caracterísitcas e efeitos da institucionalização da participação nos municípios brasileiros. IN: Avritzer, Leonardo. Experiências de participação local no Brasil. São Paulo: Cortez.

PNAS - Políticas Nacional de Assistência Social. Ministério do Desenvolvimento Social e Combate à Fome, www.mds.gov.br, Julho/2004

Rowe, G.; Frewer, L. J. (2004). Evaluating Public-Participation Exercises: A Research Agenda Science Technology Human Values. 29: 512-556

Rossi, P. H., Lipsey, M. W., \& Freeman, H. E. (2004). Evaluation: A systematic approach $\left(7^{\text {th }}\right.$ Ed. $)$. Thousand Oaks, CA: Sage

Sapori, L. F. e Wanderley, C. B. (2001). A Relação entre Desemprego e Violência na Sociedade Brasileira: Entre o Mito e a Realidade. Fundação João Pinheiro, Belo Horizonte, pp. 1-24. Manuscrito.

SNIC - Sistema Nacional de Informações sobre Cidades. Ministério da Cidades. http://www2.cidades.gov.br/geosnic/. Acessado em 20 de maio de 2010.

Worthen, B. R.; Sanders, J. R.; Jody, L. F. (2004). Avaliação de Programas. Concepções e Práticas. São Paulo: Editora Gente. 
ANEXO A - Variáveis de mensuração do conceito de vulnerabilidade social, por público-alvo e dimensão de análise, Brasil 2000

\begin{tabular}{|c|c|c|c|c|c|}
\hline \multicolumn{2}{|r|}{ Variáveis vulnerabilidade - unidade de análise: município } & \multicolumn{4}{|c|}{ Quartis de prevalência } \\
\hline \multicolumn{2}{|r|}{ Criança 0 a 14 anos } & Q1 & Q2 & Q3 & Q4 \\
\hline \multirow{2}{*}{$\begin{array}{c}\text { Trabalho } \\
\text { infantil }\end{array}$} & \% de crianças entre 10 a 14 anos proveninentes do meio rural e que trabalhavam na semana de referência & 22,7 & 22,9 & 22,9 & 31,5 \\
\hline & $\%$ de crianças entre 10 a 14 anos proveninentes do meio urbano e que trabalhavam na semana de referência & 17,1 & 31,4 & 27,4 & 24,0 \\
\hline \multirow{8}{*}{ Educacional } & \% de crianças entre $0-4$ anos proveninentes do meio rural fora da creche ou da escola & 7,8 & 53,4 & 30,5 & 8,3 \\
\hline & $\%$ de crianças entre 5-6 anos proveninentes do meio rural fora da creche ou da escola & 7,6 & 50,6 & 30,9 & 11,0 \\
\hline & $\%$ de crianças entre 7-14 anos proveninentes do meio rural fora da creche ou da escola & 23,5 & 23,5 & 22,1 & 31,0 \\
\hline & $\%$ de crianças entre $0-4$ anos proveninentes do meio urbano fora da creche ou da escola & 9,6 & 52,1 & 28,7 & 9,6 \\
\hline & $\%$ de crianças entre 5-6 anos proveninentes do meio urbano fora da creche ou da escola & 6,2 & 46,7 & 31,4 & 15,7 \\
\hline & $\%$ de crianças entre 7-14 anos proveninentes do meio urbano fora da creche ou da escola & 57,2 & 3,6 & 17,8 & 21,4 \\
\hline & $\%$ de mães provenientes do meio urbano com baixa escolaridade (menos 4 anos de estudo) & 9,7 & 52,3 & 28,3 & 9,7 \\
\hline & $\%$ de mães provenientes do meio rural com baixa escolaridade (menos 4 anos de estudo) & 7,9 & 53,0 & 30,8 & 8,3 \\
\hline \multirow{4}{*}{ Ecocômica } & \% de crianças entre 0 e 14 anos, provenientes do meio rural, cujas famílias têm renda per capita inferior à 1/2 salário mínimo & 8,2 & 52,5 & 30,7 & 8,6 \\
\hline & \% de crianças entre 0 e 14 anos, provenientes do meio urbano, cujas famílias têm renda per capita inferior à 1/2 salário mínimo & 9,6 & 51,8 & 29,0 & 9,6 \\
\hline & \% de crianças entre 0 e 14 anos, provenientes do meio rural, cujas famílias têm renda per capita inferior à $1 / 4$ salário mínimo & 10,4 & 45,9 & 31,6 & 12,1 \\
\hline & \% de crianças entre 0 e 14 anos, provenientes do meio urbano, cujas famílias têm renda per capita inferior à $1 / 4$ salário mínimo & 10,6 & 48,7 & 29,6 & 11,0 \\
\hline \multirow{6}{*}{ Familiar } & \% de crianças entre 0 e 14 anos provenientes do meio urbano cujas famílias não têm a presença da mãe & 22,8 & 13,5 & 15,3 & 48,4 \\
\hline & \% de crianças entre 0 e 14 anos provenientes do meio rural cujas famílias não têm a presença da mãe & 20,6 & 8,3 & 11,3 & 59,8 \\
\hline & $\%$ de crianças entre 10 e 14 anos, provenientes do meio urbano, cujo total de rendimentos compõe $50 \%$ ou mais da renda nominal familiar & 15,3 & 9,7 & 13,4 & 61,6 \\
\hline & $\%$ de crianças entre 10 e 14 anos, provenientes do meio rural, cujo total de rendimentos compõe $50 \%$ ou mais da renda nominal familiar & 9,4 & 6,5 & 14,1 & 70,0 \\
\hline & \% de crianças entre 10 e 14 anos, provenientes do meio urbano, cuja família divide domicílio com outras duas famílias ou mais & 16,1 & 20,3 & 23,3 & 40,3 \\
\hline & \% de crianças entre 10 e 14 anos, provenientes do meio rural, cuja família divide domicílio com outras duas famílias ou mais & 15,1 & 9,1 & 16,5 & 59,4 \\
\hline \multirow{3}{*}{ Trabalho } & Adolescentes (15 a 17 anos) e Jovens (18 a 24 anos) & Q1 & Q2 & Q3 & Q4 \\
\hline & \% de jovens entre 18 e 24 anos, provenientes do meio rural, desempregados na semana de referência & 10,0 & 48,6 & 30,6 & 10,8 \\
\hline & $\%$ de jovens entre 18 e 24 anos, provenientes do meio urbano, desempregados na semana de referência & 15,2 & 44,6 & 30,4 & 9,8 \\
\hline \multirow{4}{*}{ Educacional } & \% de adolescentes entre 15 e 17 anos, provenientes do meio rural, que não frequentam a escola & 9,3 & 48,4 & 30,8 & 11,5 \\
\hline & $\%$ de adolescentes entre 15 e 17 anos, provenientes do meio urbano, que não frequentam a escola & 9,2 & 50,1 & 30,2 & 10,6 \\
\hline & $\%$ de adolescentes entre 15 e 17 anos, provenientes do meio rural, com baixa escolaridade (menos 4 anos estudo) & 9,5 & 45,6 & 31,2 & 13,8 \\
\hline & $\%$ de adolescentes entre 15 e 17 anos, provenientes do meio urbano, com baixa escolaridade (menos 4 anos estudo) & 10,2 & 47,2 & 29,5 & 13,0 \\
\hline
\end{tabular}


$\%$ de jovens entre 18 e 24 anos, provenientes do meio rural, que não frequentam a escola

$\%$ de jovens entre 18 e 24 anos, provenientes do meio urbano, que não frequentam a escola

$\%$ de jovens entre 18 e 24 anos, provenientes do meio rural, com baixa escolaridade (menos 4 anos estudo)

$\%$ de jovens entre 18 e 24 anos, provenientes do meio urbano, com baixa escolaridade (menos 4 anos estudo)

$\%$ de adolescentes entre 15 e 17 anos, provenientes do meio rural, cujas famílias têm renda per capita inferior à 1/2 salário mínimo

$\%$ de adolescentes entre 15 e 17 anos, provenientes do meio urbano, cujas famílias têm renda per capita inferior à 1/2 salário mínimo

$\%$ de adolescentes entre 15 e 17 anos, provenientes do meio rural, cujas famílias têm renda per capita inferior à 1/4 salário mínimo

$\%$ de adolescentes entre 15 e 17 anos, provenientes do meio urbano, cujas famílias têm renda per capita inferior à 1/4 salário mínimo

Econômica

$\%$ de jovens entre 18 e 24 anos, provenientes do meio rural, cujas famílias têm renda per capita inferior à $1 / 2$ salário mínimo

$\%$ de jovens entre 18 e 24 anos, provenientes do meio urbano, cujas famílias têm renda per capita inferior à $1 / 2$ salário mínimo

$\%$ de jovens entre 18 e 24 anos, provenientes do meio rural, cujas famílias têm renda per capita inferior à 1/4 salário mínimo

$\%$ de jovens entre 18 e 24 anos, provenientes do meio urbano, cujas famílias têm renda per capita inferior à 1/4 salário mínimo

\begin{tabular}{cccc}
8,0 & 52,8 & 30,7 & 8,6 \\
9,8 & 52,1 & 28,2 & 9,8 \\
8,9 & 50,3 & 30,9 & 9,9 \\
9,7 & 51,1 & 29,5 & 9,7 \\
\hline 7,9 & 50,4 & 31,4 & 10,3 \\
9,5 & 51,5 & 29,0 & 10,1 \\
9,4 & 48,7 & 31,1 & 10,9 \\
10,6 & 40,5 & 31,4 & 17,5 \\
9,1 & 49,3 & 31,5 & 10,1 \\
12,8 & 45,1 & 31,4 & 10,8 \\
13,6 & 32,3 & 33,4 & 20,7 \\
13,3 & 38,4 & 31,4 & 16,9
\end{tabular}

\begin{tabular}{|c|c|c|c|c|c|}
\hline \multirow{6}{*}{ Familiar } & \% de adolescentes entre 15 e 17 anos, provenientes do meio urbano, cujo total de rendimentos compõe $50 \%$ ou mais da renda nominal familiar & 15,2 & 24,9 & 24,8 & 35,0 \\
\hline & $\%$ de adolescentes entre 15 e 17 anos, provenientes do meio rural, cujo total de rendimentos compõe $50 \%$ ou mais da renda nominal familiar & 15,7 & 16,9 & 21,4 & 46,0 \\
\hline & \% de adolescentes entre 15 e 17 anos, provenientes do meio urbano, com baixa escolaridade (menos 4 anos estudos) e pelo menos 1 filho & 9,3 & 9,8 & 15,9 & 65,0 \\
\hline & $\%$ de adolescentes entre 15 e 17 anos, provenientes do meio rural com baixa escolaridade (menos 4 anos estudos) e pelo menos 1 filho & 6,5 & 8,3 & 17,9 & 67,4 \\
\hline & $\%$ de jovens entre 18 e 24 anos, provenientes do meio urbano com baixa escolaridade (menos 4 anos estudos) e pelo menos 1 filho & 16,9 & 34,6 & 27,6 & 20,9 \\
\hline & $\%$ de jovens entre 18 e 24 anos, provenientes do meio rural com baixa escolaridade (menos 4 anos estudos) e pelo menos 1 filho & 21,5 & 28,4 & 24,7 & 25,4 \\
\hline & Idosos & Q1 & Q2 & Q3 & Q4 \\
\hline \multirow{6}{*}{ Econômica } & \% de pessoas com 60 anos ou mais, provenientes do meio urbano, sem rendimentos ou com rendimentos exclusivos de benefícios & 9,7 & 7,1 & 10,1 & 73,1 \\
\hline & \% de pessoas com 60 anos ou mais, provenientes do meio rural, sem rendimentos ou com rendimentos exclusivos de benefícios & 10,0 & 8,6 & 16,7 & 64,7 \\
\hline & $\%$ de pessoas com 60 anos ou mais, provenientes do meio urbano, cujas famílias têm renda per capita inferior a 1/2 salário mínimo & 10,8 & 47,2 & 29,9 & 12,1 \\
\hline & \% de pessoas com 60 anos ou mais, provenientes do meio rural, cujas famílias têm renda per capita inferior a 1/2 salário mínimo & 13,0 & 36,6 & 32,7 & 17,7 \\
\hline & $\%$ de pessoas com 60 anos ou mais, provenientes do meio urbano, cujo rendimento compõe $50 \%$ ou mais da renda nominal familiar & 9,6 & 52,3 & 28,5 & 9,6 \\
\hline & $\%$ de pessoas com 60 anos ou mais, provenientes do meio rural, cujo rendimento compõe $50 \%$ ou mais da renda nominal familiar & 10,1 & 48,4 & 31,7 & 9,9 \\
\hline Familiar & \% de pessoas com 60 anos ou mais, provenientes do meio urbano, cuja família divide domicílio com outras duas famílias ou mais & 12,5 & 20,0 & 20,9 & 46,7 \\
\hline
\end{tabular}


\% de pessoas com 60 anos ou mais, provenientes do meio rural, cuja família divide domicílio com outras duas famílias ou mais

$\%$ de pessoas com 60 anos ou mais, provenientes do meio urbano, que moram sozinhas

$\begin{array}{llll}8,0 & 6,7 & 11,0 & 74,3\end{array}$

$\%$ de pessoas com 60 anos ou mais, provenientes do meio rural, que moram sozinhas

$$
\text { PPD }
$$

Trabalho

$\%$ de PPD entre 14 e 65 anos provenientes do meio rural desempregados ou trabalhando no setor informal

$\%$ de PPD entre 14 e 65 anos provenientes do meio urbano desempregados ou trabalhando no setor informal

$\%$ de PPD, provenientes do meio urbano, sem rendimentos ou com rendimentos exclusivos de benefícios

Econômica \% de PPD, provenientes do meio rural, sem rendimentos ou com rendimentos exclusivos de benefícios

$\%$ de PPD provenientes do meio urbano cujas famílias têm renda per capita inferior a $1 / 2$ salário mínimo

$\%$ de PPD provenientes do meio rural cujas famílias têm renda per capita inferior a $1 / 2$ salário mínimo

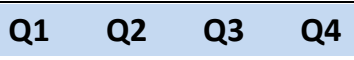

$7,3 \quad 50,2 \quad 31,1 \quad 11,5$

\begin{tabular}{llll}
15,0 & 46,1 & 28,8 & 10,2 \\
\hline
\end{tabular}

$5,5 \quad 6,7 \quad 21,0 \quad 66,9$

\section{Família}

$8,1 \quad 16,1 \quad 27,4 \quad 48,3$

$\begin{array}{llll}8,1 & 16,1 & 27,4 & 48,3 \\ 8,7 & 50,8 & 29,4 & 11,1\end{array}$

$5,6 \quad 48,4 \quad 31,7 \quad 14,4$

$\%$ de famílias, provenientes do meio rural, com renda per capita inferior à $1 / 2$ salário mínimo

Q2 $\quad$ Q3 $\quad$ Q4

\% de familias, provenientes do meio urbano,com renda per capita inferior à $1 / 2$ salário mínimo

$\%$ de famílias, provenientes do meio rural, com renda per capita inferior à $1 / 4$ salário mínimo

Econômica \% de famílias, provenientes do meio urbano, com renda per capita inferior à $1 / 4$ salário mínimo

$48,6 \quad 31,5 \quad 10,1$

$\%$ de famílias, provenientes do meio rural, com razão de dependência acima de $75 \%$

$\%$ de famílias, provenientes do meio urbano, com razão de dependência acima de $75 \%$

$\%$ de famílias provenientes do meio rural composta apenas por mãe e filhos

$\%$ de famílias provenientes do meio urbano composta apenas por mãe e filhos

Familiar

$\%$ de famílias provenientes do meio rural composta apenas por pai e filhos

$\%$ de famílias provenientes do meio urbano composta apenas por pai e filhos

$\%$ de famílias provenientes do meio rural que dividem domicílio com outras duas famílias ou mais

$\%$ de famílias provenientes do meio urbano que dividem domicílio com outras duas famílias ou mais

$\begin{array}{llll}16,5 & 33,1 & 32,9 & 17,5\end{array}$

$14,9 \quad 39,8 \quad 30,2 \quad 15,1$

$11,0 \quad 46,9 \quad 31,0 \quad 11,1$

$9,6 \quad 52,2 \quad 28,6 \quad 9,6$

$27,1 \quad 21,4 \quad 21,9 \quad 29,6$

$\begin{array}{llll}11,7 & 46,0 & 30,5 & 11,8\end{array}$

$30,6 \quad 12,2 \quad 14,2 \quad 42,9$

$62,7 \quad 9,3 \quad 6,8 \quad 21,2$

$27,8 \quad 19,6 \quad 19,5 \quad 33,1$

$\begin{array}{llll}16,3 & 36,1 & 30,2 & 17,4\end{array}$

